\title{
El Dojang: escuela de disciplina y moralidad
}

\author{
Gonzalo Ariel MILLÁN* \\ Consejo Nacional de Investigaciones Científicas y Técnicas. Programa de Posgrado en Antropología \\ Social, Universidad Nacional de Misiones (Argentina).
}

Recepción: 22/12/2014; Aceptación: 21/04/2015; Publicación: 26/04/2015.

ORIGINAL PAPER

\section{Resumen}

Las artes marciales pueden ser definidas como historia en movimiento. Pocas actividades deportivas de popularidad internacional movilizan corporalmente un repertorio simbólico y práctico de moralidad ética y sensualidad estética tan complejo y distintivo de un pueblo como las disciplinas marciales coreanas, en especial el taekwondo y el gumdo. Al igual que en otros deportes de combate, el gimnasio de artes marciales (dojang) es el lugar donde se producen y reproducen los valores y se apropian las habilidades, conocimientos y reconocimientos - títulos, certificados, etc. - que legitiman la entrega, corporal y social, de un individuo a un disciplina marcial. El presente artículo busca transmitir al lector las emociones que genera en un neófito la práctica de un arte marcial y las tensiones sociales y kinestésicas que se experimentan como resultado de esta acción en la moderna sociedad coreana. Asimismo, explora algunos factores históricos vinculados a su desarrollo y acelerada expansión en apenas medio siglo.

Palabras clave: Corea del Sur; artes marciales; deportes de combate; taekwondo; gumdo; trabajo corporal; disciplina; educación.

\begin{abstract}
The Dojang: School of Discipline and Morality Abstract

Martial arts can be defined as history in motion. Few sport activities of international fame represent a complex symbolic and practical repertory of ethic morality and aesthetic sensuality so distinctive of a nation as the Korean martial disciplines do, especially taekwondo and gumdo. Similar to other combat sports the martial arts gym (dojang) is the place where values are produced and reproduced and where the appropriation of skills, cognition and recognition degrees, certificates, and so on - that legitimates the social and bodily devotion of an individual to a martial art takes place. This article aims to transmit the emotions generated in a neophyte by the practice of a martial art and the social and kinaesthetic strains that result from this action in modern Korean society. It also explores some of the historical factors linked to its development and rapid expansion, in barely half a century.
\end{abstract}

Keywords: South Korea; martial arts; combat sports; taekwondo; gumdo; bodily labour; discipline; education.

\section{O Dô-jang: escola de disciplina e moralidade Resumo}

As artes marciais podem ser definidas como história em movimento. Poucas actividades desportivas, de popularidade internacional, mobilizam corporalmente um repertório simbólico e prático de moralidade ética e sensualidade estética tão completo e distintivo de um povo como as disciplinas marciais coreanas, em especial o taekwondo e o gum-dô. Tal como noutros desportos de combate, o ginásio de artes marcais (dô-jang) é o lugar onde se produzem e se reproduzem os valores e se apropriam as habilidades, os conhecimentos e os reconhecimentos - títulos, certificados, etc. - que legitimam a entrega, corporal e social, de um indivíduo a uma disciplina marcial. 0 presente artigo procura transmitir ao leitor as emoções que gera num neófito da prática de arte marcial e as tensões sociais e quinéticas que se experimentam como resultado desta acção na moderna sociedade coreana. Explora, assim, alguns factores históricos vinculados ao seu desenvolvimento e acelerada expansão em apenas meio século.

Palavras-chave: Coreia do Sul; Artes marciais; desportos de combate; Taekwondo; Gum-dô; trabalho corporal; disciplina; educação.

\section{Introducción}

A partir de una experiencia de estadía prolongada en Geoje-Do, isla industrial ubicada al sureste de la Península coreana, describiremos el proceso de génesis social del artista marcial en la moderna sociedad de Corea del Sur. Al describir el vínculo entre las artes marciales como

*E-mail: gonzalo.ariel.millan@gmail.com. Dirección: Bolivia 3907 (CP: 3300). Posadas-Misiones, Argentina. 
actividades generadoras de tradiciones y prácticas culturales y la estructura social de las que sonproducto, analizaremos la transformación de la conciencia colectiva (Durkheim, 2004) acerca de estas disciplinas. Perceptible en el plano de las conductas, sentimientos, gestos, movimientos, rutinas de entrenamiento, en suma, el montaje fisio-psico-social que Marcel Mauss (1979) denomina técnicas corporales, y que puesto en marcha constituye el trabajo corporal (Wacquant, 1999) del artista marcial.

Los estudios antropológicos y sociológicos sobre artes marciales y deportes de combate han avanzado considerablemente gracias al esfuerzo, no siempre articulado, de grupos de investigación e investigadores en solitario trabajando en distintas partes del mundo. Se puede decir que buena parte de esa inyección de investigaciones ha sido motivada por la etnografía seminal de Loïc Wacquant sobre los boxeadores del ghetto negro norteamericano entre fines de $1980 \mathrm{y}$ principios de 1990. Un excelente ejemplo de esto lo constituye la compilación de etnografías realizada por Sánchez y Spencer (2013), titulada Fighting Scholars. En esta obra, sus colaboradores se proponen profundizar el proyecto de sociología carnal postulado por Wacquant - siendo una de sus premisas el uso del concepto de habitus como objeto empírico y como método de investigación - en cinco direcciones temáticas: 1) técnicas corporales; 2) género; 3) etnicidad/raza; 4) religión/autotransformación; y 5) violencia/dolor. Todo esto complementado con ricas discusiones metodológicas y aportes epistemológicos centrales, no ya para el campo acotado de los estudios sobre disciplinas corporales, sino para las ciencias sociales en general. Fighting Scholars es además una imagen en pequeña escala de las tensiones y debates que existen en torno al estudio de actividades cuya principal característica es la maestría corporal.

Allí, Sánchez analiza la socialización del dolor en el proceso de convertirse en aikidoka (prácticante de aikido), como una negociación constante entre los agentes en torno a la imposición de dos umbrales de violencia, uno superior y otro inferior, en la práctica marcial. Su etnografía sobre los boxeadores y aikidokas en España muestra el efecto que el proceso de civilización descrito por Elias tiene en la forma en que ciertas personas perciben y se relacionan con el conflicto físico y la violencia. Y cómo, a su vez, este fenómeno incide en la formación de un habitus de boxeador y de aikidoka - y podríamos agregar de taekwondista - para moverse con soltura en estos espacios.

Asimismo, Graham (2013) analiza la formación de un habitus específico entre los practicantes de taekwondo en Canadá, que implica la adquisición de un conocimiento corporal para desarrollar secuencias rápidas y precisas de ataque y defensa sin tener que pensarlas antes. En el proceso el practicante remodela su ser mediante la práctica repetitiva y automatizada, para pasar del pensar y actuar a una forma de acción con intencionalidad encarnada, mediante la incorporación de técnicas corporales reflexivas (Graham, 2013: 64). Este concepto, acuñado por Crossley, busca dar cuenta de aquellas técnicas corporales cuyo propósito es actuar sobre el cuerpo, sea para modificarlo o mantenerlo en algún sentido (Crossley, 2005, p. 10). Con el objetivo de enriquecer el concepto de habitus desde una perspectiva fenomenológica, este autor retoma un programa de estudio antropológico sobre el cuerpo esbozado por Mauss en 1934, en su célebre artículo sobre Les techniques du corps.

Otros estudiosos han abordado el análisis del taekwondo desde la antropología, centrándose en las construcciones y modificaciones que ha sufrido a partir de su expansión por el mundo. Quizá el primer trabajo en este sentido sea el de Kim Min-Ho (1999), quien analiza la inserción del taekwondo en Francia a partir del concepto de técnicas corporales. El autor realiza un extenso recorrido filosófico e histórico sobre las artes marciales, comparando asimismo la forma en que se practican en Francia y en Corea del Sur, buscando extraer las características antropológicas de las modernas artes marciales.

Ya entrados en el siglo XXI, Martínez Guirao (2011) realiza una investigación sobre el taekwondo en la región de Alicante, España. Desde una mirada etnográfica centrada en el cambio sociocultural, el autor busca dar cuenta del proceso de deportivización (Elias \& Dunning, 1992) de las artes marciales, a partir de su descontextualización y aculturación en el mundo "Occidental", centrándose en lo que considera elementos primordiales de socialización en el taekwondo: el gimnasio, la clase y las relaciones sociales entre taekwondistas. Su libro contiene además una muy buena síntesis de los principales estudios académicos sobre las artes marciales, por ejemplo, las 
obras de Donohue $(1994,1998)$ sobre la construcción simbólica de las disciplinas marciales japonesas.

Como se puede ver a partir de este breve recorrido bibliográfico, el estudio antropológico del taekwondo se puede realizar desde perspectivas teórico-conceptuales distintas, incluso utilizando metodologías cualitativas diversas. En lo que estos autores coinciden, sin embargo, es en la escasez de trabajos sobre la temática que existen hasta la fecha, así como su importancia para comprender mejor las actividades corporales y los fenómenos de cambio social y adaptación cultural.

Por lo tanto, en este artículo nos proponemos penetrar a fuerza de una sistemática y extenuante rutina diaria de entrenamiento, en el aparentemente hermético y sacrosanto mundo de las artes marciales, para introducir al lector en los aspectos mundanos del aprendizaje del taekwondo y el gumdo, símbolos de identidad nacional del pueblo coreano. En las acciones y representaciones que le otorgan su particular sentido, y el sentido de representación que tiene para algunos miembros de esta sociedad, por su difusión a nivel mundial como por el prestigio y distinción que otorga at home a quienes hacen de este oficio un estilo de vida.

\section{Metodología}

En el diseño metodológico domina una estrategia cualitativa de tipo etnográfica. El trabajo está estructurado en base a la información recogida en seiscientas páginas de diario de campo durante el año y medio que residí en Corea del Sur, en especial los nueve meses que pasé en GeojeDo. En conjunto, describe escenas de la vida diaria de más de una docena de academias de Taekwondo $\mathrm{WTF}^{1}$ y gumdo en las que me desempeñé como instructor ayudante, entre seis y siete horas diarias, cinco días a la semana. También recoge mis experiencias como aprendiz del arte de la espada coreana en las academias de dos maestros de Haidong Gumdo. La selección de las academias estuvo enteramente vinculada a la red de relaciones que fui tejiendo a medida que me involucraba más en la práctica y enseñanza de las disciplinas, ya que fueron los maestros quienes me recomendaban para otras academias. En general, las escuelas ofrecían cinco o seis clases diarias de una hora a la que asistían entre 15 y 25 alumnos por turno (siendo el número de alumnos inversamente proporcional a su graduación en la disciplina). Durante este período, la edad promedio de los maestros era de 39 años, siendo la edad más baja registrada 27 y la edad más alta 53. Por el contrario, salvo contadas ocasiones, la mayor parte de los alumnos eran niños y niñas de entre 7 y 13 años.

La información principal se obtuvo aplicando la técnica de observación participante. Esta herramienta tiene un valor central para la investigación antropológica, ya que permite al investigador conocer de forma íntima las vidas de las personas en sus ámbitos cotidianos. Realizar durante un tiempo prolongado las mismas actividades que los sujetos estudiados, constituye una forma inmejorable de registrar oficios donde la mayor parte del aprendizaje se realiza con, y a través del cuerpo. Asimismo, la técnica de historia de vida se utilizó para reconstruir las trayectorias familiares, laborales y propiamente marciales de mis dos maestros de gumdo. Sus experiencias vitales me permitieron comprender las características y consecuencias del extraordinario proceso de desarrollo económico, educativo y social que experimentó el pueblo coreano durante el siglo XX. Así como los avatares históricos que les permitieron compatibilizar la

\footnotetext{
1 La razón que llevó a un practicante de taekwondo de la International Taekwondo Federation (ITF) a convertirse en instructor en academias de la World Taekwondo Federation (WTF) en su lugar de origen, es bastante sencilla. A partir de un contrato con una asociación llamada ITF-Korea, que busca desde el 2005 reintroducir esta variante de TKD en Corea del Sur (donde el común de la gente la asocia negativamente a su vecino del Norte), un grupo de instructores junior de distintas partes del mundo terminamos recalando en diversas regiones de Corea del Sur. Allí, a falta de gimnasios de ITF, fueron los mismos maestros de WTF quienes hicieron el vínculo con la Asociación, a fin de que enseñáramos clases de TKD en inglés para sus alumnos. Lo que esta experiencia me enseñó, aunque al principio me pareció muy chocante dada la acentuada diferenciación entre TKD ITF y WTF que impera en el mundo Occidental, es que en Corea existe una concepción del taekwondo que tiene el potencial de funcionar como un lazo simbólico y cultural que atraviesa las fronteras nacionales de la península. La contraparte, es decir la mirada sobre el TKD WTF desde el Norte, la aprendí gracias a un valiente joven $2^{\circ}$ dan de TKD ITF proveniente de Corea del Norte, que luego de fugarse con mucho riesgo pero con éxito de su país, terminó compartiendo conmigo el alquiler de un departamento en Busan durante dos meses.
} 
enseñanza del gumdo, disciplina relativamente desconocida en la región sureste de la península hacia fines de la década de 1980, con los esquemas morales y prácticos de la cultura fabril masculina de los astilleros.

Las conversaciones cotidianas e informales, principal forma de registro discursivo de este trabajo, se realizaron en inglés durante los primeros meses. Posteriormente, tomé cursos intensivos de lengua coreana en la Busan Foundation for International Activities (BFIA) hasta el final de la estadía. El manejo del idioma se convirtió en una pieza clave para acceder a niveles más profundos de las representaciones de mis informantes, así como a situaciones sociales donde el uso del inglés es inexistente. A fin de hacer más fluida la lectura todos los diálogos fueron traducidos al español.

\title{
3. Las academias de artes marciales en Corea del Sur
}

El dojang, adaptación del término japonés dojo, es el término coreano con que se designa el espacio de práctica de artes marciales. La siguiente descripción hecha por el fundador del taekwondo, se puede aplicar casi literalmente a todas las disciplinas marciales, así como a diversos deportes de combate:

\begin{abstract}
Es el área donde hombres y mujeres, ancianos y jóvenes sin distinción de raza o credo, llegan para aprender Taekwon-Do para mejorar su educación mental, moral, física y cultural. Debe ser un lugar donde un cierto "espíritu de camaradería" debe ser establecido entre sus miembros, con la intención de lograr y cultivar un carácter noble... El lugar de entrenamiento debe tener las facilidades y equipo, y las estrictas regulaciones que ayudarán a que el alumno discipline su mente y su cuerpo" (Choi, 1996, p. 368).
\end{abstract}

Al subir los últimos escalones para llegar al gimnasio se siente que algo particular está ocurriendo al otro lado de la puerta. El aire silencioso es cortado sistemáticamente por exhalaciones secas y simultáneas con un sonido peculiar, como un silbido contenido. Cuando ingresa, el visitante se topa de frente con una multitud ordenada de cuerpos en movimiento, que destilan una imagen de homogeneidad notable, inducida por dos motivos visuales: la vestimenta y el estilo de práctica. Como monjes en sus sotanas, los alumnos visten trajes blancos ceñidos al cuerpo por coloridos cintos, ocultando los rasgos que en otras esferas de la vida cotidiana funcionan como vehículos de signos (Goffman, 2001). Además, la práctica repetitiva y comunitaria que reúne a diario a los mismos grupos de personas, produce un "ritmo" colectivo que vuelve los gestos de los alumnos casi idénticos. El rol didáctico asignado a los alumnos más versados contribuye a generar este efecto. Casi sin proponérselo los veteranos son modelos de "carne y hueso" que colaboran en la socialización del resto de los alumnos tanto como el instructor. Por ello, este siempre aconseja "seguir a los cintos superiores".

Bajo la intensa luz de los fluorescentes a lo largo y ancho del techo, se despliegan coreografías con técnicas ágiles, potentes y coordinadas. El ruido distintivo de la respiración, el crack! de los uniformes cuando un golpe veloz quiebra momentáneamente sus pliegues almidonados o los gritos enérgicos al unísono, cuando se ejecuta una patada, son los pocos sonidos que se escuchan en los minutos de máxima concentración durante la ejecución de una forma (tul o poomse, para el taekwondo; gumpap para el gumdo).

Para preservar el ambiente pulcro, el piso de goma que amortigua el rebote de los pies descalzos es fregado entre clase y clase. En las paredes color ocre cuelgan tablillas de madera escarbadas con los "Principios" del arte, especie de mantra recitado en comunión al inicio o al final de cada sesión.

Al frente de la clase, bajo el amparo de la bandera coreana, el Sabum-nim (instructor) supervisa los movimientos con mirada severa, corrigiendo la técnica de un alumno en particular o, frecuentemente, de forma colectiva: "bajen más el codo en la defensa con canto de mano, cubran las costillas" y "los dedos de la mano bien cerrados", son lecciones que esconden en el uso del plural un mensaje dirigido a un alumno concreto, mientras fuerza a todos a prestar mayor atención. Es uno de los elementos que permiten al principiante desarrollar técnicas corporales reflexivas (Crossley, 2005; Graham, 2013), esto es, formas de actividad corporal estructuradas, obtenidas mediante la 
repetición, que permiten la ejecución de técnicas marciales de manera precisa y automatizada, sin la necesidad de razonar acerca de ellas.

Al igual que un capataz pendiente de la mirada y gestos del patrón, el instructor es un observador que se sabe observado pues, tras el cristal de su oficina, de espalda a los alumnos, el Kwanjang-nim (maestro) controla de tanto en tanto el desarrollo de la clase, sin embargo rara vez irrumpe en el espacio de práctica. La ubicación cuasi panóptica de su oficina colabora en el disciplinamiento del cuerpo (Foucault, 1996), instaurando un estado de vigilancia casi permanente. De esta manera, supervisa la actividad de los estudiantes, aunque la mayor parte del tiempo lo pasa hundido en su sillón frente a la computadora diseñando cronogramas de actividades, inmerso en las tareas administrativas de su academia y, a menudo, mirando catálogos de compra online o distendiéndose en videojuegos.

Así, todos los aspectos del entrenamiento predisponen a un tipo de comportamiento regulado, disciplinado y coordinado; controlado colectivamente, ya que cada alumno hace de espejo al resto, y también auto-controlado (Guk Gi) - como reza uno de los cinco "Principios" -, pues la apropiación de las técnicas se realiza a fuerza de un ejercicio de resocialización fisiológica y emocional. La rutina repetitiva que prepara al cuerpo para desarrollar los movimientos acrobáticos y potentes que dan fama a las disciplinas marciales, solo puede soportarse mediante la concentración extrema del practicante las semanas o meses previos a un examen, y la sensación de satisfacción que proporciona la adquisición de una nueva graduación.

\section{El Gohyeon Gumdo Cheyukwan'}

El gimnasio donde forjé mis primeras armas en el arte de la espada está ubicado cerca de la capital de la isla, a pocas cuadras del astillero de Samsung. Dos afiches de dibujos estilo manga vestidos con uniformes de gumdo y agitando sus espadas de madera en posturas de ataque, cubren la puerta de vidrio de acceso a la academia de Hwang Beom June, maestro quinto dan del arte coreano de la espada. Los pisos superiores del edificio albergan una escuela privada de música y una de matemáticas. En el último piso funciona un cibercafé cuya clientela habitual son los "Samsung men" (obreros de la fábrica) que salen del trabajo a las seis de la tarde, juegan algunas partidas de videojuegos en internet y luego se pierden en algún bar con luminosos carteles de neón unas calles más abajo, cerca del puerto.

A diferencia del estilo sobrio y más bien opaco de la academia de Park In Myeong (su maestro), el gimnasio de Hwang está saturado de cuadros, posters y objetos de entrenamiento que ocupan desordenadamente las paredes y rincones. Espadas de madera con el nombre de cada alumno escrito con tinta negra en el mango, reposan en soportes colgados de la pared blanca entre ventana y ventana. El parqué está cubierto de finas láminas de goma ocre de un metro cuadrado, ensambladas hasta cubrir cada loza del piso. En el techo cuelgan las tres banderas que no pueden faltar en una academia: la bandera coreana en el centro, a la derecha la de la Federación Mundial de Haidong Gumdo (WHGF según sus siglas en inglés), y a la izquierda la de la Asociación Coreana de Haidong Gumdo (KHGA, por sus siglas en inglés). Ambas organizaciones son presididas por el Gran Maestro Kim Jeong Ho.

En la pared opuesta a la entrada hay una ventana de vidrio que rara vez está abierta y al lado la bandera de la Asociación. La silueta bordada en dorado de un hombre realizando un corte de espada mientras salta por los aires, es la insignia de esta organización. Arriba del dibujo, en letras blancas, se lee "Haidong Gumdo" en caracteres chinos y coreanos, seguidos de los nombres de la Asociación de Geoje que dirige Park y la Asociación Coreana, a la que pertenecen ambas academias. A su lado, casi tapado por las banderas, hay un pequeño cuadro con una foto de Park más joven, vestido con un impecable traje de gumdo blanco mientras realiza un saludo marcial con los brazos frente al cuerpo y las manos alineadas, sosteniendo una espada imaginaria que apunta hacia abajo. Es la forma simbólica en que Hwang rinde homenaje a su maestro y designa intencionalmente la posición de su dojang en la jerarquía de escuelas de la isla. Más a la derecha se exhibe un cuadro rectangular de un pergamino con una larga bendición budista escrita en elegante caligrafía china. Este símbolo protege el lugar contra los malos

\footnotetext{
2 Para preservar la intimidad de mis informantes, todos los nombres de academias, maestros y alumnos han sido alterados.
} 
deseos y trae buena fortuna a su propietario. Debajo del cuadro hay un soporte del que cuelgan una vieja espada de metal sin filo, que Hwang solía usar para entrenar, y dos espadas de madera con un peso varias veces superior a las normales (que tienen entre trescientos y quinientos gramos). Lo que más llama la atención del visitante, quizá por contraste, es un póster blanco plastificado con un gigantesco ideograma chino en el centro, seguido de la información del sitio web del gimnasio y un pizarrón blanco sujeto a la pared, lleno de coloridos garabatos con los nombres de los alumnos y los turnos a los que asisten. También hay seis cuadros con los Principios del Gumdo escritos en tinta negra, acompañados de la foto de un practicante vistiendo ropas de entrenamiento que lucen recién lavadas y ejecutando diferentes posturas (las fotos fueron tomadas por la Asociación y son colgadas voluntariamente por los maestros de academias en todo el país).

La oficina del maestro es un escondite tras una puerta corrediza de vidrio, a través de la cual puede controlar el desarrollo de la clase. Su dimensión real no se percibe hasta que se la atraviesa. Adentro se erige un verdadero altar privado al gumdo. Una espada guardada en una vaina exquisita llena de dibujos cuelga de una pared y, extrañamente, el mango de madera quebrado le da un toque de solemnidad. En un rincón hay una biblioteca con libros especializados de historia coreana, artes marciales y educación física. Encima del mueble, a modo de estante, se exhiben varios trofeos y medallas de torneos. También hay un sofá con una mesa ratona y un escritorio con computadora y dos sillas; una muy cómoda y de mayor precio, para el maestro, la otra más rudimentaria, para el instructor.

Al costado derecho, fuera de la oficina del maestro, dos tabiques cerrados por persianas de madera sirven de vestuario para niños y niñas; un mueble alto con cajones cuadrados a la vista guarda las armaduras azul oscuro (iguales a las que hay en el gimnasio de Park) para entrenamientos de combate. Y sobre una silla, una televisión cuadrada de veintiún pulgadas conectada a una consola de videojuegos, que cada tanto el maestro autoriza a sus alumnos a usar cuando no tiene ganas de encargarse de la parte recreativa de la clase, o durante los campamentos nocturnos de fines de semana, que ofrece la academia como programa adicional a las clases de gumdo. Y que las madres aprecian mucho, como lo indica el bajísimo porcentaje de ausentes a dichos eventos. (Nota del diario de campo, junio de 2008).

\section{Una práctica mimética}

A lo largo del tiempo los artistas marciales han ido produciendo una monumental literatura de tipo emic, en la que a menudo se describe la lógica del aprendizaje marcial en términos que refieren el carácter pre-lógico de la práctica (Bourdieu \& Wacqüant, 2005). La actitud descrita como "mente de principiante" (Iedwab \& Standefer, 2001) alude a un estado prístino en que el practicante (avanzado) deja sus pensamientos conscientes de lado, aplicando la "no-mente", permitiéndole entrenarse de manera fluida mediante la "unidad del cuerpo y el espíritu". Estos eufemismos poseen un carácter filosófico profundo que define con precisión la sabiduría carnal y práctica del "aprendizaje visual y mimético" de las disciplinas corporales (Wacquant, 2006, pp. 112119).

La dinámica de los entrenamientos está diseñada para capitalizar esta faceta de la enseñanza. Aunque el cuerpo individual es en última instancia el medio y objeto de trabajo en las artes marciales, los ejercicios de elongación y estiramiento que preparan las articulaciones antes de la práctica, las coreografías mediante las cuales se aprenden las nuevas técnicas, las combinaciones continuas de patadas y golpes a objetivos fijos y móviles, los ataques y defensas previsiblemente pautados para sentir la técnica en acción, en suma, todos los elementos que comprenden la rutina del oficio, son realizados en conjunto. Por ello, los practicantes que rompen la simetría colectiva son reprendidos por el instructor con frases irónicas que aluden a la falta de control corporal y, a menudo, con castigos que separan momentáneamente al "infractor", que debe aislarse del grupo para completar una serie de lagartijas o saltos de rana.

\section{1. "La rutina es la clave para mejorar"}

Al igual que en las rutinas repetitivas de las fábricas, la sensación de monotonía y tedio que agobia a los trabajadores durante periodos más o menos prolongados y regulares no es extraña 
para el alumno de taekwondo o gumdo. Con variaciones mínimas, la rutina de entrenamiento tiene las mismas características en todos lados: calentamiento, ejercicios básicos, formas, ejercicios de lucha pautados, lucha libre y estiramiento. En un vector ininterrumpido, cada secuencia prepara el cuerpo y la mente para el próximo paso mediante un ritmo ascendente continuo, hasta que coinciden en un momento álgido del entrenamiento el nivel más elevado de flexibilidad, concentración y emoción que el alumno puede alcanzar. A partir de ese momento el instructor experimentado fuerza la voluntad de sus alumnos para exigirles un poco más.

Mientras estiro los abductores en un rincón veo llegar de a poco los practicantes del último turno. El dojang tiene capacidad para cincuenta alumnos pero hoy somos apenas una docena. Entre ellos hay algunos adultos que como yo salen de sus trabajos a las siete u ocho de la tarde con algo de tiempo para ejercitar antes de volver a sus casas.

Formados en filas de cuatro de cara al frente del dojang, Choi (un tercer dan de 25 años) ordena el saludo a la bandera coreana, la bandera de la federación y al maestro, en ese orden. Hincando la rodilla derecha en el piso, cada practicante deposita con ambas manos su espada de madera (mokgum), con el filo apuntando hacia él; para levantarla se debe apoyar la otra rodilla. Choi dirige una serie de ejercicios básicos de entrada en calor en el lugar. Saltamos un poco rotando los brazos, codos y muñecas en varias direcciones y la sensación de calidez comienza a recorrer mi cuerpo. Dos alumnos a mi derecha lucen desganados y rebotan ligeros sobre sus pies mientras cuchichean en voz baja hasta que Kim, el segundo alumno más avanzado, los reprende. Al finalizar, una delgada lámina de transpiración me recubre la frente y unas gotas se deslizan por mis manos.

El maestro Park nos mira inquietos mientras juega con su espada de madera, realizando cada tanto un veloz corte en el aire para acomodar los músculos. Su delgada figura se pierde tras una columna que tapa mi visión. A la voz de chariot! (atención) reaparece ágilmente ubicándose frente a la clase. Imitando a mis compañeros coloco ambos pies juntos, los puños en la cintura y los codos hacia atrás. Recojo mi espada de práctica con ambas manos, colocándola del lado izquierdo, como si estuviese dentro de una vaina atada al cinto; la mano derecha con el puño armado vuelve a su lugar. De un vistazo, el maestro chequea las posturas, deteniéndose para corregir un codo demasiado abierto y el brazo de un alumno que cuelga muerto con la espada apenas agarrada. Paff!, de un coscorrón el alumno se pone recto como una tabla.

El maestro se para frente a la clase y con voz chillona dice "kimayase, chumbi...siyak" (posición de jinete, preparados...comiencen). Separamos los pies hacia los costados, primero las plantas solares y luego los talones mientras Choi cuenta cuatro veces, hasta alcanzar una apertura de casi medio metro. Al completar la postura - que constituye la base y principio de cualquier ejercicio con el sable - los talones quedan hacia afuera y las rodillas hacia dentro. Entonces bajamos el centro de gravedad de la cadera, flexionando las rodillas en una posición muy incómoda. Park esboza una sonrisa por mi cara de disgusto, mientras empiezo a sentir el dolor en mis rodillas desacostumbradas a esta postura. Una vez afirmada la posición de jinete (kimayase) el maestro da la orden de desenvainar: beltot! No estaba completamente desorientado gracias a Hwang, quien me había adelantado algunos de los movimientos básicos. Al unísono todos realizamos un largo corte horizontal con la espada en la mano derecha, hasta alinearla con ambos hombros del lado opuesto. Empuño la espada con ambas manos al frente y empujo el mango hacia atrás hasta que la espada se pierde de mi rango de visión por encima de la cabeza. Chequeando a mis compañeros de adelante percibo que tengo los brazos demasiado rectos y flexiono los codos. La espada desciende lentamente hacia delante con el filo hacia abajo y la punta del mango casi tocándome el ombligo. En comparación con Choi y Kim, mis movimientos parecen torpes y siento los músculos agarrotados.

Desde el frente Park nos indica que enfoquemos la mirada en un oponente ficticio al alcance de la espada, e imaginemos que cada corte lo atraviesa. Aunque tengo la sensación de que se dirige únicamente a mí, por las caras de indiferencia con que lo miran mis compañeros. Al final agrega: "Do you understand, Gonzalo?", en un inglés tosco pero seguro, aumentado así su prestigio frente a sus discípulos, que miran al maestro anonadados. Park posee un manejo del inglés sumamente pobre y, dado que la gran mayoría de sus alumnos tampoco maneja esta lengua con fluidez, unas pocas palabras dichas con soltura y naturalidad, a pesar de la pronunciación, llaman la atención de todos, incluido yo, que contesto "yes, sir" a pesar de haber practicado cientos de veces la respuesta afirmativa en coreano. 
"Il, i, sam, sa..." (Uno, dos, tres, cuatro). El conteo arranca demasiado rápido y apenas tengo tiempo para chequear los movimientos. Me dejo fluir y sigo el ritmo de mis compañeros. Siento la madera golpear torpemente mi espalda cuando llevo la espada hacia atrás, pero no puedo controlarlo. En lugar de seguir una línea recta de atrás a adelante mi espada se bambolea como una bandera flameando. "Ship" (diez), Choi se calla, Kim retoma automáticamente el conteo. El sudor de mis manos se acrecienta y noto que el agarre empieza a resbalar. "I ship", ¿Recién veinte cortes? Kim es relevado por el alumno en tercer lugar; aparentemente todos vamos a contar. Preocupado, recuerdo que sólo me sé los números hasta el cuarenta, y estoy décimo en la fila. Decido que voy a contar en inglés. El cinto comienza a desajustarse y presiento que se va a caer. Park camina alrededor de las filas con los nudillos dentro del cinto y los brazos en jarras, evitando escrupulosamente el contacto con sus alumnos, salvo cuando realiza una corrección precisa o pierde el quicio ante un practicante indisciplinado. A uno de los alumnos más chicos se le resbala la espada hacia atrás y rebota en el piso. Apresurado se da vuelta para levantarla pero el maestro ya está encima de él, reprendiéndolo. Le tocan veinte flexiones de brazo y diez saltos.

"O ship" (Cincuenta). El quinto alumno comienza a contar. Cuando empiezo a sentirme cómodo con la posición, Park a mi derecha me dice que está todo mal. Golpea mi rodilla con su pie forzándome a flexionarla más. La punzada de dolor no tarda en llegar. Se para delante de mí permitiéndome visualizar el oponente que debo atravesar. Me indica que al cortar, la muñeca debe quedar recta.

Antiguamente la muñeca se flexionaba por completo, dando al corte mayor potencia y recorrido. "Ahora - me había comentado Hwang - los alumnos empiezan desde niños y tenemos que cuidar sus articulaciones". La regresión de la edad mínima para iniciar la práctica ha venido de la mano de varias modificaciones, que fueron surgiendo a medida que se iba adaptando la enseñanza a los requisitos del nuevo mercado marcial, y a las disposiciones mentales y corporales del nuevo segmento de practicantes.

El maestro asiente y sigue su recorrido. Cuando creo que ya se fue, siento otro golpe en el talón derecho para que lo apunte hacia afuera, y casi resbalo con el charco de sudor que rodean mis pies. El golpe de mi espada de madera en la espalda comienza a molestarme. Con el dobok (uniforme de práctica) sudado suena como un trapo húmedo golpeado contra el piso.

A diferencia de los golpes de taekwondo, en los que se imprime velocidad y rotación a los miembros durante la ejecución de un golpe de puño o patada, en gumdo la velocidad debe ser constante, ya que la potencia del corte viene del amplio recorrido de la espada, a la que hay que visualizar como parte de uno mismo, "la extensión de tu propio brazo", como le gusta decir a Hwang.

Noventa. Falta poco para mi turno y siento los brazos completamente inflamados. Las mangas del dobok prestado me quedan muy ajustadas y el roce en las axilas me produce un escozor molesto. Mis manos se sienten al rojo vivo (pienso en los ampollas que me esperan). Para intentar asombrar a mis compañeros decido contar hasta diez en coreano ${ }^{3}$, lo que provoca una media sonrisa en la cara de una ajuma (señora) de pelo corto que se da vuelta para mirarme. Solo hay dos mujeres en el gimnasio. Ambas son mayores que el maestro Park y amigas de él hace varios años, así que las reglas de etiqueta entre ellos no son tan estrictas.

Los dos últimos compañeros cuentan veinte cortes más y Choi al inicio de la clase retoma el conteo, mientras Park parece perder interés y desaparece tras su oficina (probablemente a fumar un cigarrillo, como suelen hacer algunos maestros a escondidas durante la clase, especialmente cuando tienen instructores como Choi o Kim que pueden quedar a cargo).

I peg (doscientos). Hace rato dejó de molestarme el dobok completamente desaliñado y el cinto casi por las rodillas. Siento una dolorosa contractura en los hombros y el cuello, y tengo que modificar la postura de las piernas porque siento como si me estuvieran clavando alfileres en las rodillas. Veo que algunos compañeros dejan colgar una mano mientras continúan los cortes con la otra, y los imito. En mi palma ya empiezan a dibujarse las ampollas. Doscientos cincuenta cortes. Al cambiar de brazo encuentro que la derecha está aún peor; una ampolla ha explotado causando una leve pero constante molestia. Mis brazos se mueven en piloto automático.

\footnotetext{
${ }^{3}$ El coreano posee dos sistemas numéricos, uno de influencia china y otro nativo, que fue el usado por mí. Al final de la clase Park me informa que para el conteo de cortes utilizan el sistema chino, pero a pesar de mi ignorancia valora el intento.
} 
Un alumno de trece años me chista con cara de disgusto. Shit! Es mi turno y no me di cuenta. Demasiado agotado para contar en coreano comienzo en inglés y, para mi sorpresa, Park ubicado al frente de la clase comienza a gritar con cada corte. Todos lo imitamos. El ambiente se revitaliza con la adrenalina que generan los gritos (Kiai). Los cortes parecen más fuertes y rápidos, aunque las caras apenas pueden esconder el cansancio. Siento que mi último corte puede partir cualquier cosa a la mitad. Park grita beltot! (envainar) y nos mira con gesto de aprobación mientras guardamos la espada en la vaina imaginaria y la depositamos en el piso. Como recompensa tenemos tres minutos para refrescarnos en el tanque de agua al final del dojang antes de continuar la clase. De reojo miro el reloj de plástico colgado en una columna. Apenas han pasado veinte minutos... la clase recién comienza. (Nota de campo, mayo de 2008).

\section{El sentido social de la práctica marcial}

En tanto artefacto y tradición cultural el taekwondo constituye un sistema de prácticas y rituales objetivados en una matriz generadora (Wacquant, 1999). La distinción entre costumbre y tradición establecida por Hobsbawm (2002) resulta útil para diferenciar el sentido de los distintos elementos prácticos y simbólicos de que se compone esta disciplina marcial. En tanto sistema de entrenamiento para la defensa personal el taekwondo constituye una costumbre de considerable antigüedad en Corea, interrumpida durante la ocupación nipona mediante un decreto que prohibía a los coreanos practicar artes marciales (Wagner, Carter, lee, Lew, \& Robinson, 1990). Por otro lado, como proyecto de identidad nacional este arte marcial tuvo éxito en construir un puente con un pasado milenario, unificando mediante una serie de rituales y símbolos, eventos y personajes históricos en una concatenación ininterrumpida desde la mítica fundación del pueblo Han en el 2333 A.C, hasta los movimientos de resistencia durante la ocupación japonesa en la primera mitad del siglo XX. Constituye, pues, una verdadera tradición inventada (Hobsbawm, 2002), y un espacio de lucha por la imposición de la "historia verdadera".

En este sentido, conjuga y sintetiza algunas de las principales tradiciones filosóficas, eventos históricos y posturas políticas del pueblo coreano. Como resultado de un proceso social dinámico, este artefacto cultural (Vogel, Mello, \& Barrios, 2014) ha ido experimentando en sus distintas fases de expansión y reproducción, adaptaciones en los niveles filosófico y técnico. Tales cambios no son pasivos sino que, por el contrario, generan tensiones y rupturas frecuentes.

Si consideramos que cada oficio posee una ética que se expresa en una determinada forma estética, podemos explorar la influencia de las transformaciones políticas, económicas y educativas de Corea en la enseñanza de las disciplinas marciales. El sentido social y la rutina de entrenamiento de estas prácticas corporales se ha ido reestructurando acorde Corea pasó de ser una sociedad rural, analfabeta y sumamente pauperizada a una sociedad industrial desarrollada y con un elevado nivel de vida (Kim, 2008). Concebidas originalmente como sistemas de entrenamiento para la guerra, la difusión de las artes marciales en la sociedad civil significó un mayor acento en la faceta deportiva y el bienestar físico durante la socialización de los practicantes. Fuera de los entrenamientos de taekwondo obligatorios para todos los coreanos adultos que pasen por el servicio militar, lo que queda en los gimnasios actuales son una serie de metáforas bélicas en torno al cuerpo. En este contexto de rápidas transformaciones sociales, las estrategias desplegadas por los artistas marciales para la transmisión de su oficio han cambiado considerablemente en apenas una generación.

\section{El oficio tradicional devenido en profesión. Un futuro incierto...}

Una encuesta realizada en 1990 indicó que el 90\% de los alumnos primarios de Corea tomaban clases particulares en academias privadas. "La mayoría de estas clases eran en áreas tales como el tae kwon do y el atletismo, pero cada vez más los padres invertían dinero en clases académicas, en especial de lengua inglesa, ya que se pensaba que era una gran ventaja comenzar desde la infancia" (Seth, 2008, p. 227).

La inclusión de las artes marciales en el currículum básico de los estudiantes durante los años de educación formal, en especial durante la primaria y la escuela media, implicó una 
metamorfosis de forma y contenido, en disciplinas caracterizadas por la adhesión activa a valores tradicionales. La disminución de la edad mínima de iniciación en la práctica marcial, contribuyó en producir una nueva pedagogía que involucra la actualización - e incluso eliminación - de algunos de los elementos centrales que desde hace no tantos años definían el espacio físico y simbólico de las artes marciales. Una ventaja visible de la participación de estas disciplinas en la vorágine competitiva de ofertas académicas y deportivas conocida como fiebre educativa (kyoyuk yolgi) (Lee, 2006), ha sido la creciente profesionalización del oficio. En la actualidad los maestros que se dedican únicamente a enseñar artes marciales pueden obtener una remuneración económica suficiente para vivir, y algunas veces ascender en la escala social. El sentimiento de satisfacción que produce en los trabajadores el reconocimiento simbólico y material de sus trabajos por parte de la sociedad, coexiste en el caso de los artistas marciales con una sensación de que no todo cambio es bueno.

Una crítica constante que los maestros profieren contra el modelo educativo actual consiste en la cantidad de horas que los alumnos deben pasar en academias privadas. En términos de trabajo corporal esto implica que los instructores deben reducir la exigencia física en los entrenamientos. De lo contrario, el desgaste diario sería imposible de sobrellevar tanto para los alumnos como para ellos mismos. Las actitudes frente a estas modificaciones van desde una aceptación indiferente hasta una frustrada resignación.

Joel: Ya sabes, man, a los chicos hay que hacerlos hacer cosas. No importa qué hacen, sólo que se muevan un poco, hablen un poco y que se rían, ¿ok? Pasarla bien (Have a good time). Lo único que importa es que las mamás estén contentas". (Estudiante coreano de educación física y ayudante de clase en una academia de Busan, 20 años).

Hwang: "Cuando estoy al frente de una clase sé que soy maestro... pero mi día normal se divide entre niñera (babysitter) y oficinista (officeman)" (Maestro quinto dan de gumdo en Geoje-Do, 34 años).

Muchos maestros no identifican en sus pupilos el respeto que ellos profesaron a sus superiores. Los niños coreanos cada día se atreven a desafiar más las relaciones jerárquicas y se niegan a acatar de manera directa la autoridad. Para esto cuentan con el aval de sus madres, que los "alientan a ser rebeldes", en palabras de Lee. Este instructor de treinta y dos años, ayudante en la academia de Hwang, cuida con celo el respeto de las tradiciones confucianas en el ámbito marcial. Comienza las clases - especialmente la de los practicantes más jóvenes - con diez minutos de genuflexiones, mientras los niños de siete y ocho años repiten frases respetuosas de saludo en tono pausado y atento. Si alguno levanta la cabeza antes de la orden, todo el grupo es castigado con diez flexiones de brazo, diez abdominales, diez saltos de rana y deben correr hasta la pared opuesta del gimnasio y volver a sus lugares antes de que Lee cuente ocho. De lo contrario tienen que recomenzar.

Cuando los maestros que protagonizan esta investigación eran alumnos, estaba prohibida la práctica de artes marciales para menores de doce años. También era prácticamente nula la presencia de mujeres. El estilo de enseñanza en éste período me fue descrito como austero y de una considerable intensidad física y emocional.

"Antes las prácticas eran más duras - se queja Lee -, no era raro que algún alumno terminase con una lesión o fractura de dedo. Se entrenaba y se peleaba con mokgum (espadas de madera). Pero hoy no [chasquido con la lengua]... no se puede hacer por los chicos".

Park - el maestro de gumdo con la mayor graduación en Geoje-Do - se inició en la práctica marcial siendo un púber, y experimentó la emoción de entrenar con una espada (shingum) durante su adolescencia. Una práctica selecta que hoy en día se reserva para los alumnos adultos con cinto negro. A pesar de que prohíbe por completo el uso de espadas entre los jóvenes, a causa del riesgo físico que suponen, no se cansa de contar con emoción contenida el temor que le provocaba ver el filo brillante de la espada en sus manos. Y, más a menudo, usa estas anécdotas de manera ejemplar para corregir a sus alumnos cuando sostienen desganados las espadas de madera. (Nota de campo, junio de 2008). 


\section{8. ¿Arte marcial o deporte de combate?}

El carácter contradictorio de las categorías de clasificación que informan sobre el lugar de las artes marciales en el espacio de las actividades deportivas - patente, por ejemplo, en la incómoda distinción entre arte marcial y deporte - se ve claramente en el caso del mercado de bienes materiales "indispensables" para entrenar. Hace cincuenta años, cuando las disciplinas marciales coreanas no tenían siquiera eventos de competencia deportiva, Choi Hong Hi se enorgullecía de lo económico de la práctica de taekwondo, que "puede efectuarse en cualquier lugar, aun sin los elementos necesarios", siendo "una de las ventajas principales de este arte" (Choi, 1996, p. 368). El proceso de profesionalización de las artes marciales que ha permitido la espectacular expansión de las mismas en Corea, presiona a los maestros a convertir sus gimnasios en mercados de abastecimiento donde los alumnos pueden comprar los nuevos cintos, trajes, espadas o protectores, además de una variedad impresionante de artículos de consumo deportivo. De esta manera, un maestro con habilidades comerciales puede hacer una diferencia en las finanzas de su academia.

Otro ejemplo de la hipertrofia de oferta marcial generada por la competencia entre academias, fue la aparición de una prestación que se expandió rápidamente en todo el campo educativo coreano. El servicio de transporte "pick up", como lo llaman los nativos, es indispensable en cualquier hagwon (academia) que se precie de tal. Consiste en buscar a los alumnos donde sea que se encuentren, para llevarlos a la academia y luego volver a transportarlos, al final de la clase, hacia el siguiente destino, que usualmente es alguna academia de inglés, matemáticas o música, por nombrar las más frecuentes. En algunos casos los alumnos están tan dispersos que se tarda más de cuarenta minutos en agruparlos a todos, obligando a los maestros y profesores que conducen sus propios vehículos a "descargar" el grupo en la academia, sólo para partir de inmediato a buscar los alumnos del siguiente turno y llevar a los que acaban de terminar. Por este motivo, una de las primeras acciones que emprenden los empresarios de la educación que empiezan a prosperar, consiste en contratar un conductor. En el caso de las artes marciales esta figura se condensa en el instructor ayudante, que alternativamente puede conducir el vehículo del dojang mientras el maestro dirige la clase y viceversa.

En actitud de repudio ante este giro comercial - y también porque es uno de los damnificados de la mutación descrita - el maestro Park se limita únicamente a proveer uniformes de práctica y cintos para sus alumnos y a dirigir y manejar sólo las actividades de su academia, una de las más antiguas de Geoje-Do. A pesar de ello, él mismo se ha visto atrapado en la corriente de consumo, transformando su oficina en una verdadera armería, con dos arcos tradicionales y seis espadas (de mil dólares cada una) adquiridas en los últimos diez años, además de su primer espada que le costó casi tres mil dólares.

\subsection{Del Arte de la Guerra al fair play deportivo y el cuidado corporal}

Actualmente los instructores coreanos exigen a sus alumnos un elevado nivel de autocontrol en los enfrentamientos. En las academias de taekwondo se insiste en que hay que cuidar al compañero de práctica porque "está prestando su cuerpo", reduciendo la violencia del combate al mínimo durante los entrenamientos. Por un lado, a través del uso de pecheras y cascos de protección, de acuerdo a los requisitos deportivos. Por el otro, reemplazando accesorios que en otros tiempos eran considerados indispensables. Son aquellos que sirven para adiestrar al estudiante en las técnicas de defensa personal y desarrollar la anatomía que le permite ejecutar golpes con la potencia suficiente para dejar a un contrincante fuera de combate, como los sacos, la práctica de rotura de tablas y la lucha libre donde no rigen las reglas deportivas. Incluso el uso del dobok, vestimenta ceremonial distintiva de las artes marciales, se ha vuelto laxa. Los instructores y maestros son comprensivos con aquellos alumnos que traen una vestimenta deportiva o incluso ropa de calle - jeans y remera - pues vienen de una clase previa en alguna academia privada nodeportiva. Y luego del entrenamiento probablemente tengan que ir con la misma ropa a seguir estudiando en otro lugar.

Los sacos pesados (heavy bags) en los que los alumnos pueden "aterrizar" patadas sin tener que controlar la fuerza, tampoco pasan de ser un adorno en los gimnasios modernos. Entre una 
docena de gimnasios donde entrené o impartí clases, sólo uno preservaba los sacos colgados. Asumiendo que se utilizaban con frecuencia, organicé un entrenamiento con ejercicios de patadas, exigiendo que los alumnos aumentasen la potencia progresivamente. Para mi sorpresa, durante la primera ronda el cuarto alumno de la fila sufrió una lesión en el pie al patear. El maestro me advirtió desde su oficina que evite usar el saco y al final de la clase me confesó que su propósito es meramente decorativo. "Los alumnos ya no usan los sacos. Hoy en día se busca el punto [en competencias deportivas] y para eso entrenamos velocidad, no fuerza" (Young, maestro de taekwondo sexto dan, 45 años). Los sacos fueron desplazadas por las palmetas, para practicar el "foco" y la precisión, especialmente porque permiten entrenar complicadas y vistosas técnicas aéreas, que requieren poca o nula potencia. Estos atractivos saltos son ejecutados en exhibiciones así como en torneos, aunque su utilidad durante un combate real es dudosa, debido a la prolongada pérdida del punto de apoyo que requieren.

Las formas (como se ha dicho, poomse o tul para el taekwondo, gumpap para el gumdo) son dispositivos claves de socialización técnica y moral de las artes marciales, que también han sufrido adaptaciones. Son, citando un Manual de Taekwondo ITF:

Sucesiones de diversos movimientos fundamentales, la mayoría de los cuales representan técnicas de ataque o defensa, establecidos en secuencias fijas o lógicas. El estudiante tiene que hacer frente, sistemáticamente, a varios adversarios imaginarios en condiciones diversas, utilizando todos los miembros de ataque o posiciones posibles y en cualquier dirección... El tul, pues, registrando cada movimiento, es una serie de lucha, potencia, proezas y belleza caracterizada (Choi, 1996: 524).

El taekwondo cuenta con una veintena de formas divididas en categorías de grados o cintos que sirven a los fines prácticos de aprender de manera dinámica los más de dos mil movimientos que componen la disciplina. Su ejecución sistemática durante las sesiones de entrenamiento contribuye al desarrollo de una coordinación psico-motriz fina y simétrica en los practicantes, comparable, al menos en parte, a los movimientos que los obreros de fábricas de tipo fordista llegan a dominar tras mucho tiempo de repetición. En las artes marciales, sin embargo, el dominio se ejerce con todo el cuerpo.

Para lograr esto los maestros diseccionan y evalúan minuciosamente cada movimiento de sus discípulos. El ángulo de los pies, la posición de rodillas y cadera, la distribución del peso corporal, la relajación o contracción del vientre, el porte de la espalda y los hombros, la rotación de las muñecas y tobillos, la colocación de las manos y dedos, una respiración coordinada y la vista enfocada en un punto determinado, son los principales aspectos que se tienen en cuenta. Todo esto simulando un combate contra uno o más oponentes, con o sin armas, en solitario o con aliados.

Sin embargo, en la actualidad la estética deportiva impone una mayor atención a la vistosidad que en la preocupación por la aplicación real de una técnica. En los torneos se premia, y en los gimnasios se entrena, la realización de movimientos que deforman por exageración el sentido de un golpe. Las patadas ejecutadas en un ángulo cada vez más vertical, que disminuye la potencia y estabilidad, se han introducido como un requisito altamente valorado en las competencias. Otro ejemplo son las llamadas "formas musicales": ejecución de un poomse coordinando los desplazamientos al ritmo de una canción, normalmente de género pop o tecno.

Después de un entrenamiento en el gimnasio de Kim (maestro sexto dan de treinta y ocho años, dueño de una academia con el sugerente nombre de "Hanmi Taekwondo Dojang"4), conversamos sobre el tema de las formas musicales. Despreocupado por las implicancias de ésta modalidad sobre la práctica en general, zanjó el asunto explicándome que "es lo que se evalúa en los torneos. Además, las madres adoran ver a sus hijos haciendo patadas altas y bailando" (Nota de campo, agosto de 2008).

\footnotetext{
4 Literalmente, "Academia de Taekwondo Norteamericano". La academia fue inaugurada a los pocos meses de mi llegada a la isla. Posteriormente Hwang, su amigo, me confió que había decidido llamarla así cuando llegó a sus oídos que había un instructor de taekwondo extranjero que daba clases en inglés, sin importarle demasiado que fuese argentino. Incluso después de que yo me trasladara a otra ciudad pasado un año, la academia siguió conservando el nombre, aún a falta de instructor extranjero y de clases en inglés.
} 
Se percibe, siguiendo a Bourdieu (2007), una eufemización de la violencia, en tanto se produce un distanciamiento entre el practicante y el oponente. Este proceso de reducción del tipo e intensidad de violencia tolerada por los practicantes en un contexto de entrenamiento marcial, contribuye a disminuir el umbral de violencia (Sánchez, 2013) considerado normal en el espacio de práctica y produce un efecto sobre la forma en que los estudiantes de éstas disciplinas perciben y experimentan el conflicto físico. Según este autor, la negociación de la violencia permitida en las prácticas de artes marciales afecta la capacidad de los practicantes para lidiar con potenciales enfrentamientos, así como la forma en que se experimentan los rasgos emocionales asociados al combate físico.

Al sopesar los efectos de estas variaciones sobre sus trabajos no son pocos los maestros que expresan sentimientos ambivalentes. Aprecian el hecho de que a diferencia de la generación anterior de maestros, existe hoy la posibilidad de dedicarse "a tiempo completo" (full time) en la enseñanza de artes marciales. Esta transformación, sin embargo, deja más desprotegidos en el oficio a aquellos maestros socializados en un período anterior, al introducir nuevas reglas de juego que desequilibran los pilares del sentido común de los artistas marciales: la autoridad de la jerarquía y el prestigio de la antigüedad. En efecto, la faceta deportiva de las disciplinas se ha transformado en un terreno de lucha por la imposición de una nueva estética que expone e impone un sentido completamente distinto en el entrenamiento de artes marciales en Corea del Sur, afectando los patrones previos de negociación de la violencia (Sánchez, 2013). En este proceso de metamorfosis se ha ido redefiniendo la lógica que lleva a un sujeto a optar por seguir una carrera como artista marcial.

\section{Consideraciones finales}

A partir de un análisis etnográfico, hemos mostrado los efectos del fenómeno de socialización de las nuevas generaciones de artistas marciales en Corea del Sur. El aprendizaje de una disciplina marcial como el gumdo o el taekwondo implica un importante ejercicio de resocialización física y emocional, que tiene por efecto poner al neófito en contacto con una serie de representaciones sociales acerca de Corea y su historia. Así, el entrenamiento marcial produce al mismo tiempo una serie de habilidades físicas y de disposiciones mentales muy particulares, que fuerzan al estudiante a prestar atención a determinados aspectos de la cultura coreana.

Como artefacto cultural el taekwondo sintetiza dos fenómenos que venían manifestándose en los ámbitos educativos de Corea durante el siglo XX: la consolidación de un sistema ético y moral propiamente oriental, por un lado, y la asimilación de los principios racionales y conocimientos científicos de Occidente, por el otro. Al definirlo Choi se enorgullecía escribiendo, "es el resultado de los principios tradicionales, éticos y morales de Oriente" y "las técnicas físicas del Taekwon-Do se basan sobre los principios de la ciencia moderna en particular de la física de Newton quien nos enseña el modo de generar máxima potencia" (Choi, 1996, p. 24). Estas características le permitieron insertarse rápidamente en una sociedad coreana deseosa de asimilar lo que consideraban lo mejor de Occidente, sin por ello perder contacto con sus propios valores y filosofía.

Tampoco se debe subestimar la importancia del ingreso del taekwondo en el plano internacional, en especial si se considera que su creación ocurre cuando Corea acababa de salir de una cruenta ocupación por parte de Japón, que tuvo un efecto devastador en términos sociales. El taekwondo y las artes marciales que le siguieron, vinieron a posicionar a Corea en el plano internacional como un pueblo resistente y con una importante tradición de cultivación corporal y filosófica. Paradójicamente, en 1979 el entonces Director del Museo Nacional de Corea se lamentaba, durante una exhibición de arte oriental en San Francisco, de que "la Guerra de Corea y el taekwondo eran casi las únicas cosas que la gente conocía de Corea” (Korea Focus, 2013).

Las modernas disciplinas marciales coreanas se han vuelto tan importantes en la socialización del pueblo coreano que no han podido permanecer al margen de los cambios y exigencias del proceso de deportivización (Elias \& Dunning, 1992). Como resultado, las organizaciones de artes marciales y los maestros experimentan una constante tensión para incorporar los estilos de enseñanza que les exigen los campos deportivo y educativo. Como se ha intentado mostrar, este proceso tiene muy diversos resultados entre aquellos sujetos que hacen de

Rev. Artes Marciales Asiát., 10(1), 1-15 2015 
la enseñanza de artes marciales un oficio de vida. Cabe preguntarse hasta qué punto estos esfuerzos adaptativos son capaces de preservar aquellos elementos que constituyen el núcleo de estas disciplinas y que las distinguen de otras actividades físicas y deportes de combate

\section{Referencias}

Bourdieu, P., \& Wacquant, L. (2005). Una invitación a la sociología reflexiva. Buenos Aires: Siglo XXI Editores.

Bourdieu, P. (2007). Programa para una sociología del deporte. En Cosas Dichas (pp. 173-184). Barcelona: Gedisa.

Choi H. H. (1996). Taekwon-Do. El arte coreano de la defensa personal. Buenos Aires: International Taekwon-Do Federation.

Crossley, N. (2005). Mapping Reflexive Body Techniques: On Body Modification and Maintenance'. Body \& Society, 11(1), 1-35.

Donohue, J. J. (1994). Warrior Dreams: The Martial Arts and the American Imagination. Westport, CT: Bergin \& Garvey.

Donohue, J. J. (1998). Herding the Ox. The Martial Arts as Moral Metaphor. Wethersfield, CT: Turtle Press.

Durkheim, E. (2004). La división del trabajo social. Buenos Aires: Libertador.

Elias, N., \& Dunning, E. (1992) Deporte y ocio en el proceso de la civilización. México: Fondo de Cultura Económico.

Foucault, M. (1996). La verdad y las formas jurídicas. Barcelona: Gedisa.

Goffman, E. (2001). La presentación de la persona en la vida cotidiana. Buenos Aires: Amorrortu.

Graham, E. (2013). 'There Is No Try in Tae Kwon Do': Reflexive Body Techniques in Action. En R. Sánchez \& D. Spencer (Eds.) Fighting Scholars. Habitus and Ethnographies of Martial Arts and Combat Sports (pp. 63-77). London \& New York: Anthem Press.

Hobsbawm, E. (2002) Introducción: la invención de la tradición. En E. Hobsbawm \& T. Ranger (Eds.), La invención de la tradición (pp. 7-21). Barcelona: Crítica.

Iedwab, C. A., \& Standefer, R. L. (2001). El arte secreto de la salud y la buena forma física. Madrid: Miraguano.

Kim, K. D. (Ed.). (2008). Social Change in Korea. Paju: Jimoondang.

Kim, M.-H. (1999). L'origine et le developpement des arts martiaux. Pour une anthropologie des techniques du corps. Paris: L'Harmattan.

Korea Focus. (2013, 13 de marzo). The Korean Wave Creeps into Cultural Heritage. Korea Focus. Recuperado http://www.koreafocus.or.kr/design3/Culture/view.asp?volume id=137\&content id=104670\&category $=\mathrm{C}$

Lee J. K. (2006). Educational Fever and South Korean Higher Education. Revista Electrónica de Investigación Educativa, 8(1), 1-14.

Martínez Guirao, J. E. (2011). Una etnografía de las artes marciales. Procesos de cambio y adaptación cultural en el taekwondo. Alicante: Editorial Club Universitario.

Mauss, M. (1979). Técnicas y Movimientos Corporales. En Sociología y Antropología (pp. 335-356). Madrid: Tecnos.

Sánchez, R., \& Spencer, D. (Eds.) (2013). Fighting Scholars. Habitus and Ethnographies of Martial Arts and Combat Sports. London \& New York: Anthem Press.

Sánchez, R. (2013). Taming the Habitus. The Gym and the Dojo as 'Civilizing Workshops'. En R. Sánchez \& D. Spencer (Eds.) Fighting Scholars. Habitus and Ethnographies of Martial Arts and Combat Sports (pp. 155-170). London \& New York: Anthem Press.

Seth, M. J. (2008). Fiebre educativa: sociedad, política, y el anhelo de conocimiento en Corea del Sur. Buenos Aires: Prometeo.

Vogel, A., Mello, M. A. da S., \& Barrios, J. F. P. de (2014). La gallina de Angola. Buenos Aires: Antropofagia.

Wacquant, L. (1999). Un arma sagrada. Los boxeadores profesionales: capital corporal y trabajo corporal. En J. Auyero (Comp.), Caja de herramientas. El lugar de la cultura en la sociología norteamericana (pp. 237-292). Buenos Aires: Universidad de Quilmes. 
Wacquant, L. (2006). Entre las cuerdas. Cuadernos de un aprendiz de boxeador. Buenos Aires: Siglo XXI Editores.

Wagner, E. W., Carter, J. E., Lee K. B., Lew Y. I., \& Robinson, M. (1990). Korea Old and New: A History. Seúl: Ilchokak.

\section{Author's biographical data}

Gonzalo Ariel Millán es Licenciado en Antropología Social y becario doctoral del CONICET en el Programa de Posgrado en Antropología Social (PPAS-UNaM). Desarrolló su investigación para la tesis de grado a partir de una estadía prolongada en Corea del Sur (2008-2009). En ese tiempo dictó clases de taekwondo y tomó clases de Haidong Gumdo. Es tercer dan de Taekwon-Do ITF y segundo dan de Haidong Gumdo. E-mail: gonzalo.ariel.millan@gmail.com. 